\title{
ASSISTÊNCIA MULTIPROFISSIONAL À MULHER VÍTIMA DE VIOLÊNCIA: ATUAÇÃO DE PROFISSIONAIS E DIFICULDADES ENCONTRADAS
}

Daniela Anderson Carvalho Costa르. Juliana Freitas Marques², Karla de Abreu Peixoto Moreira ${ }^{3}$, Linicarla Fabíole de Souza Gomes ${ }^{4}$, Ana Ciléia Pinto Teixeira Henriques ${ }^{5}$, Ana Fátima Carvalho Fernandes ${ }^{6}$

RESUMO: Objetivou-se identificar o papel de profissionais atuantes em serviço de referência à mulher vítima de violência e descrever as dificuldades encontradas. Estudo descritivo, qualitativo, realizado em centro de referência em atendimento à vítimas de violência, em Fortaleza-Ceará, entre setembro e outubro de 2009. Foram entrevistados 20 profissionais atuantes no serviço, cujos dados foram coletados e analisados, conforme a técnica de análise de narrativas. Os resultados mostram que as mulheres seguiam fluxo de atendimento por meio da equipe multidisciplinar, com a assistência de profissionais de nível elementar, médio e superior. Os profissionais enfatizaram diversos obstáculos relacionados à ressocialização das vítimas, a não aceitação de acompanhamento psicológico e a escassez de recursos humanos. Enfatiza-se a necessidade de maior interação da rede de saúde com os serviços de referência, proporcionando a reestruturação emocional e social da mulher vítima de violência. DESCRITORES: Saúde da mulher; Violência doméstica; Equipe de assistência ao paciente.

\section{MULTIPROFESSIONAL ASSISTANCE TO THE WOMAN WHO IS A VICTIM OF DOMESTIC VIOLENCE: THE PROFESSIONALS’ FUNCTIONING AND THE DIFFICULTIES FOUND}

ABSTRACT: The aim was to identify the role of the professionals acting in a service of excellence for women who are victims of domestic violence, and to describe the difficulties found. This descriptive and qualitative study was undertaken in a center of excellence in treating victims of violence, in Fortaleza-Ceará, between September and October 2009. Interviews were held with 20 professionals working in this service; their data was collected and analyzed in line with the technique of analysis of narratives. The results show that the women followed a route of attendance via the multidisciplinary team, with the assistance of professionals from the elementary, middle and higher levels. The professionals emphasized various obstacles related to the re-socialization of the victims, their refusal to accept psychological follow-up, and the scarcity of human resources. The need is emphasized for greater interaction of the healthcare network with the services of excellence, providing emotional and social restructuring of the woman who is the victim of violence. DESCRIPTORS: Woman's health; Domestic violence; Patient care team.

\section{ASISTENCIA MULTIPROFESIONAL A LA MUJER VÍCTIMA DE VIOLENCIA: ACTUACIÓN DE PROFESIONALES Y DIFICULTADES ENCONTRADAS}

RESUMEN: Estudio cuyo objetivo fue identificar el papel de profesionales actuantes en servicio de referencia a la mujer víctima de violencia y describir las dificultades encontradas. Estudio descriptivo, cualitativo, realizado en centro de referencia en atendimiento a las víctimas de violencia, en Fortaleza, Ceará, entre septiembre y octubre de 2009. Fueron entrevistados 20 profesionales actuantes en el servicio, cuyos datos fueron obtenidos y analizados de acuerdo con la técnica de análisis de narrativas. Los resultados muestran que las mujeres seguían flujo de atendimiento por medio del equipo multidisciplinar, con asistencia de profesionales de nivel elementar, medio y superior. Los profesionales enfatizaron diversos obstáculos acerca de la resocialización de las víctimas, la no aceptación de acompañamiento psicológico y la escasez de recursos humanos. Se destaca la necesidade de más interacción de la red de salud con los servicios de referencia, proporcionando la restructuración emocional y social de la mujer víctima de violencia. DESCRIPTORES: Salud de la mujer; Violencia doméstica; Equipo de asistencia al paciente.

${ }^{1}$ Enfermeira do Centro de Atenção Psicossocial da Prefeitura Municipal de Fortaleza- Ceará. Especialista em Gestão dos Sistemas e Serviços de Saúde e Saúde da Família.

${ }^{2}$ Enfermeira. Mestre em Cuidados Clínicos em Saúde. Professora do Curso de Enfermagem da Universidade Federal de Alagoas - Campus de Arapiraca. ${ }^{3}$ Enfermeira Obstetra da Maternidade Escola Assis Chateaubriand da Universidade Federal do Ceará - MEAC UFC e da Secretaria Estadual de Saúde do Ceará. Doutoranda em Enfermagem pela UFC. Professora da Faculdade Metropolitana de Fortaleza - FAMETRO. Líder do Grupo de Estudos e Pesquisas em Enfermagem Obstétrica- GEPEO.

${ }^{4}$ Enfermeira da MEAC UFC. Mestre em Enfermagem. Doutorando em Enfermagem pela UFC. Professora da FAMETRO.

${ }^{5}$ Enfermeira. Mestre em Saúde Pública. Professora da FAMETRO. Coordenadora do GEPEO.

${ }^{6}$ Enfermeira. Doutora em Enfermagem. Professora do Curso de Graduação em Enfermagem da UFC.

Autor correspondente:

Karla de Abreu Peixoto Moreira

Secretaria de Saúde do Estado do Ceará

Av. Almirante Barroso, 600 -60060-440 - Fortaleza-CE-Brasil

E-mail: karladeabreupm@hotmail.com
Recebido: $12 / 10 / 2012$ Aprovado: 30/04/2013 


\section{INTRODUÇÃO}

A violência contra a mulher, considerada fenômeno complexo e presente no cotidiano da vida contemporânea, foi gerada a partir de processo histórico e cultural de subalternidade, relacionada à incapacidade de autodeterminar-se sexual e socialmente. Assim, a mulher se torna mais vulnerável à violência física e emocional, na medida em que não se torna sujeito da própria vida ${ }^{(1)}$. No âmbito da saúde, a introdução da problemática da violência contra a mulher aconteceu por meio do movimento feminista, no final do século $\mathrm{XX}$, em que se buscou sensibilizar a sociedade para consciência de gênero, determinando que o Estado apoie às vítimas. Este não apenas por meio do tratamento de lesões e traumas decorrentes da violência em si, mas reconhecendo-as como cidadãs, sujeitos de direito, capazes de decidir sobre suas próprias vidas ${ }^{(2)}$.

Como problema social, a violência contra a mulher é objeto de movimentos sociais, pertencendo ao âmbito da justiça e segurança pública. No entanto, esta problemática não é exclusiva ao setor saúde, mas de vários setores socialmente articulados. Essa articulação aparece na concepção ampliada do processo saúde-doença como perspectiva social, referindo-se a qualquer agravo e ameaça à vida, condições de trabalho e relações interpessoais ${ }^{(3)}$. No entanto, no cotidiano das diversas práticas sociais e de saúde, os profissionais não têm sido instrumentalizados com tecnologias específicas para abordagem de fenômenos complexos. $\mathrm{A}$ atenção à mulher vítima de violência, seja física, sexual ou psicológica é, muitas vezes, impregnada de preconceitos e reiteração das desigualdades ${ }^{(3)}$.

Os profissionais que atuam com o fenômeno da violência devem se posicionar como facilitadores do processo terapêutico, construindo estratégias que contemplem e respeitem o contexto social e as singularidades das mulheres. Para que isso ocorra, é necessário se aproximar das realidades vivenciadas pelas vítimas da violência e fornecer visibilidade aos conflitos subtendidos durante as queixas, em perspectiva multidisciplinar ${ }^{(4)}$. A atuação multidisciplinar é aquela formada por vários profissionais de diferentes especialidades, atuando como grupo, havendo necessidade de interrelação entre a equipe, a qual deve reconhecer o paciente como um todo, em atitude humanizada ${ }^{(5)}$. Os profissionais que atuam no setor saúde têm importante papel nesse contexto, pois a visibilidade da violência contra a mulher, bem como o aumento da demanda de casos desta natureza nos serviços de saúde, exige, de forma crescente, conhecimento e preparo dos profissionais de saúde, com vistas ao alcance de assistência resolutiva ${ }^{(6)}$.

No tocante à assistência profissional, as vítimas de agressores e de outras formas de violência, podem contar com programas de apoio na resolução de problemas familiares, tanto governamentais quanto não governamentais $^{(7)}$. Uma das estratégias utilizadas para oferecer suporte às mulheres em situações de violência refere-se à implantação de Centros de Referência, estruturas de prevenção e enfrentamento à violência contra a mulher. Estes visam promover a ruptura da situação de violência e construção da cidadania, por meio de ações globais e de atendimento multiprofissional (psicológico, social, jurídico e de saúde) ${ }^{(8)}$. Os serviços de referência se encontram em posição privilegiada para identificar e referir vítimas de violência, uma vez que são considerados 'portas de entrada' para a maioria dos atendimentos prestados à população, principalmente à mulheres.

Portanto, diante da problemática apresentada, bem como da carência de estudos em relação à atuação profissional no acolhimento à mulher vítima de violência, surgiu o seguinte questionamento: como ocorre a assistência prestada às mulheres vítimas de violência doméstica por profissionais que atuam em centro especializado de referência?

O estudo pretende contribuir para maior divulgação dos serviços existentes no atendimento à mulher vítima de violência, como no caso do centro de referência especializado, além de estimular a produção científica da área da saúde e enfermagem, contribuindo para que profissionais possam identificar, apoiar e fornecer o devido encaminhamento às vítimas de violência.

Para efetivar a pesquisa, objetivou-se identificar o papel de profissionais atuantes no serviço para a mulher vítima de violência e descrever as dificuldades encontradas no serviço ao lidar com a mulher violentada.

\section{MÉTODO}

Estudo descritivo, com abordagem qualitativa, realizado em Centro Estadual de Referência e Apoio à Mulher Vítima de Violência (CERAM), em Fortaleza - Ceará. Trata-se de instituição a serviço do Estado que presta atendimento à mulheres em situação de violência ou testemunha, que necessite de orientação, além de oferecer atendimento integral e humanizado às vítimas. $\mathrm{O}$ serviço contava, na ocasião do estudo, com 24 profissionais da equipe interdisciplinar. Dentre 
estes, um enfermeiro, dois psicólogos, um sociólogo, uma psicopedagoga, uma assistente social, um ginecologista, quatro defensores públicos, duas recepcionistas, quatro vigilantes, dois servidores gerais e dois motoristas. A parte administrativa era subdividida em três cargos: um chefe de unidade, um chefe de seção e uma diretora geral.

Participaram da pesquisa os profissionais vinculados à instituição, com exceção da socióloga, que se encontrava de licença; de dois vigilantes noturnos, uma vez que os mesmos não tinham contato com a rotina do Centro de Referência; e de uma defensora pública, por estar sempre em atendimento. Ao final, 20 profissionais, de nível elementar, médio e superior, que faziam parte da equipe interativa da instituição, constituíram o corpus da pesquisa.

A coleta de dados foi realizada por meio de entrevista semiestruturada, no próprio serviço, entre setembro e outubro de 2009. Os dados qualitativos foram analisados pela técnica de análise de narrativas, na qual se considera a narrativa da entrevista em detalhes e de acordo com o contexto de vida.

A entrevista narrativa compreende cinco passos: preparação do campo, com informações sobre o uso do gravador e orientações ao entrevistado; fase de iniciação, com formulação das questões norteadoras para narração; narração central, cuja informante narrará sobre as questões solicitadas; fase de questionamentos, na qual poderão ser utilizadas perguntas que possam estimular o entrevistado para o surgimento de algo novo; fase conclusiva, em que será desligado o gravador e realizadas perguntas do tipo 'por quê?'(9).

Para análise das informações, utilizou-se a técnica de análise de narrativas. Ao se obter as primeiras informações, estas se processaram mediante os seguintes procedimentos: as entrevistas foram transcritas na íntegra, transformadas em um texto; leitura do material e transformação nas unidades de análise; foram iniciadas a interpretação com a leitura de cada unidade de análise; releitura atenta para identificação das unidades de significação, no contexto da compreensão de cada narrativa, as quais foram codificadas de acordo com o sentido expresso; do agrupamento das unidades de significações, formaram-se as unidades de sentido, interpretadas no diálogo com autores ${ }^{(9)}$.

No estudo em questão, foram estabelecidas duas unidades de sentido a partir das unidades de significação: contexto da assistência multiprofissional no centro de referência; dificuldades encontradas pela equipe multiprofissional do centro de referência.
O estudo foi aprovado pelo Comitê de Ética em Pesquisa da Maternidade-Escola Assis Chateaubriand (CEP/MEAC/UFC), conforme parecer n. 070/09. Para efetivação da pesquisa, houve consentimento dos participantes, por meio da assinatura do Termo de Consentimento Livre e Esclarecido. As narrativas dos profissionais foram identificadas pela letra "P", seguida de um número cardinal $(1,2 \ldots 20)$.

\section{RESULTADOS}

\section{Contexto da Assistência Multiprofissional em Cen- tro de Referência}

O centro de referência, lócus do estudo, constitui um local que oferece suporte para que as mulheres vítimas de violência possam ter amparo, tanto emocional como jurídico. Para atendimento qualificado e holístico, as vítimas seguem determinado fluxo de atendimento, passando pelos vários profissionais da equipe multidisciplinar.

Ao chegar, as mulheres são encaminhadas à recepção, local em que é preenchida uma ficha específica, reportando os dados de identificação da vítima. As narrativas a seguir demonstram como os profissionais que atuavam na recepção da instituição percebiam a sequência do fluxo de atendimento, ao descreverem seus papéis.

[...] eu faço o primeiro acolhimento, que é preencher uma ficha com os dados e depois dessa ficha, eu vou encaminhá-la ou à assistente social, primeiramente, ou depois à defensoria e após elas virem de um desses setores, eu marco para a psicologia, porque, independentemente da situação, elas têm direito como usuário à defensoria, à assistente social e, também, à psicologia. No caso de alguma coisa mais urgente, elas estejam precisando de ginecologista ou dentista, ou um caso mais sério, a gente faz o encaminhamento por aqui tipo CAPS [Centro de Atenção Psicossocial] ou para elas serem atendidas nos hospitais de referência. (P2)

Em seguida, as mulheres são encaminhadas para o acolhimento grupal, instituído por um trabalho com dinâmicas de grupo, realizado por uma psicopedagoga, como forma de promover maior interação entre as mulheres, e momento de descontração, uma vez que estas chegam ansiosas, temerosas e preocupadas. $\mathrm{O}$ foco principal é o resgate inicial da autoestima: 
[...] é desenvolvido desde um acolhimento permanente em situação de qualquer tipo de violência ocorrida por sua condição de mulher, promovendo meios através de dinâmicas de grupo e oportunizando o fortalecimento da autoestima que é o ponto que eu [psicopedagoga] vou abrangendo mais. (P5)

Após o acolhimento em grupo, as vítimas são encaminhadas ao atendimento individual. Os profissionais responsáveis por esse atendimento são enfermeiro, assistente social ou psicólogo, que procuram transmitir à vítima da violência compreensão empática, na tentativa de reduzir as barreiras colocadas por elas.

[...] no acolhimento, eu gosto de receber as mulheres logo na entrada, eu gosto assim, que elas se sintam muito à vontade, eu gosto que elas se sintam muito protegidas, eu gosto de recebê-las na porta, com atenção, com carinho, para elas se sentirem realmente bem à vontade e que ela possa contar a sua história e a gente tentar ajudar dentro do que a gente tenha as condições. (P7)

Esse acolhimento é fazer com que a mulher se sinta bem à vontade, falando sobre a história de vida dela, para que posteriormente ela vá para os outros profissionais [...]. A gente faz com que ela tente perceber através do olhar, do suporte, como ela se encontra [...]. (P10)

Além dos serviços na área da saúde, o centro dispunha de atendimento jurídico. Na defensoria pública, era realizado trabalho de orientação sobre os serviços disponíveis na rede de atendimento para essas mulheres, além de consultoria jurídica.

Aqui na defensoria, a gente presta toda orientação, consultoria na área jurídica, tanto criminal como civel sobre os direitos das mulheres em situação de violência, orientando sobre como fazer, o que deve ser feito, que tipos de serviços existem na rede de atenção às mulheres em situação de violência. Nós fazemos encaminhamento, diagnosticamos quando é caso de abrigamento [...]. Também nós orientamos no tocante ao pedido de medidas protetivas da Lei Maria da Penha e sobre todos os direitos que a mulher vitima de violência tem, juntamente com os filhos, para que ela possa romper o ciclo da violência com tranquilidade e se sinta realmente apoiada, acolhida na sua demanda. (P8)
O centro de referência contava, ainda, com outros profissionais que, mesmo de forma indireta, atuavam na assistência à mulher. Dentre os profissionais, destacou-se o motorista da defensoria, que fazia o percurso da Delegacia para o Centro ou vice-versa, trazendo as mulheres para atendimento na instituição.

A orientação que me deram sobre o trajeto, de tanto levar as mulheres do Centro para Delegacia da Mulher como para trazer, é ter o respeito que a gente sempre tem que ter, porque são mulheres sofridas entendeu, são mulheres que precisa de um certo tratamento. Então, eu sou orientado a quê, a trazer para cá [Centro] sem perguntar, sem forçar mais alguma coisa com essas pessoas porque são pessoas já sofridas que vêm já para resolver seus problemas e tudo mais, e de repente, se você vai perguntar alguma coisa pode causar um constrangimento um pouco maior para elas. (P17)

Esse profissional era orientado quanto à questão da violência e de como tratar as usuárias que chegavam para atendimento, nos limites impostos pela instituição.

\section{Dificuldades encontradas pela Equipe Multiprofis- sional do Centro de Referência}

A maioria dos profissionais que trabalhava com as vítimas de violência, relatava dificuldade no desenvolvimento das ações, constituindo-se, muitas vezes, em obstáculos ao atendimento. Uma das dificuldades citadas pelos profissionais foi a barreira formada pela própria vítima que, geralmente, vem embutida de vergonha, constrangimento, insegurança, medo, sendo este referido como o principal empecilho ao atendimento.

A primeira dificuldade que a gente encontra realmente é quebrar a barreira do silêncio, do medo, da vergonha, do constrangimento, da insegurança [...]. (P12)

A principal dificuldade mesmo é o medo que elas têm, o receio de não dar certo, de virem, de falarem, o medo dele também, da agressividade, do comportamento dele, da reação. $(\mathrm{P} 1)$

Outro obstáculo relatado pelos profissionais que trabalhavam no serviço referiu-se à ausência de rede de apoio que ofereça oportunidades a essas mulheres para que estas sejam ressocializadas.

[...] a mulher, às vezes, não tem uma condição financeira apropriada, ela é muito dependente, tanto emocio- 
nal como psicológica e financeiramente do esposo, boa parte delas [...] ai que a gente tenta buscar, encaminhar para alguma assistente social para que ela possa arranjar, assim, algum curso, alguma coisa, tirá-la desse ambiente assim tão sofrido, é muito difícil. (P4)

Reconhece-se, pois, a necessidade de programas sociais que disponibilizem cursos profissionalizantes e contribuam para autonomia financeira de mulheres vítimas de violência, como forma de amenizar o problema vivenciado.

Os profissionais que realizavam apoio psicológico/emocional encontravam, na maioria das vezes, resistência das mulheres em aceitar esse serviço pelo preconceito das vítimas ao associarem, erroneamente, o suporte psicológico ao transtorno mental, como depoimento:

[...] outra dificuldade é a não aceitação dela mesma: "Não, eu não quero psicólogo, eu não preciso de psicólogo". É aquele preconceito e aquela falsa ideia de que o psicólogo é só para doido, então há uma resistência, e não chegam a entrar em contato com elas, com o seu verdadeiro eu. (P1)

A desinformação da vítima de violência constitui-se em outra dificuldade, uma vez que a maioria das mulheres percebe a violência como natural, que vem incrustada na vida desta desde a infância, o que exige atendimento cuidadoso, principalmente pela dificuldade de mudar a cultura enraizada há anos, como relatado:

[...] muitas delas nascem num quadro familiar em que a violência faz parte do cotidiano, elas nascem, crescem acreditando que a violência é uma coisa natural. Elas são habituadas a serem agredidas verbal ou fisicamente pelos pais, pelos irmãos, pelos parentes e levam isso para toda existência, acreditando que a mulher é um ser mais frágil e que ela tem que aceitar. (P17)

A escassez de recursos humanos e materiais é realidade vivenciada em serviços de saúde e centros de apoio que prestam atendimento à mulher em situação de violência. A narrativa de um profissional participante referiu que a mulher não deixava de ser atendida, mas sempre faltava algo que inviabilizava o atendimento:

Existem as dificuldades, carência de profissional, isso está em toda a rede [...] muitas mulheres que vêm violentadas sexualmente precisam também de medicação [...] no caso do estupro, se não tiver logo em seguida o anticoncepcional de urgência, ela corre o risco de engravidar e isso é uma coisa que a gente tenta evitar o máximo possivel. Às vezes, a gente está desprovida da medicação, do profissional, no caso a ginecologista [...] e assim não deixa de ter algumas dificuldades. (P11)

Outra dificuldade apontada a seguir remete às deficiências da rede de saúde. Os profissionais detectaram necessidades que, de imediato, não poderiam ser resolvidas no contexto do centro de referência, havendo a necessidade de encaminhamento para outros serviços do Sistema Único de Saúde (SUS).

É realmente muito conflitante na hora em que a gente está trabalhando, porque nós trabalhamos com uma rede de apoio e essa rede de apoio nem sempre é o apoio que aquela mulher está precisando [...] então, causa certa angústia quando você chega a um nivel de tanta discussão e de tanto correr e você não está encontrando o outro braço do atendimento da assistência à mulher. (P10)

\section{DISCUSSÃO}

A mulher vítima de violência, ao chegar ao serviço de referência, segue o fluxo de atendimento interno, que se inicia com o acolhimento pelo profissional da recepção, responsável em coletar os dados iniciais e realizar a triagem para os atendimentos subsequentes.

As instituições que acolhem esse segmento, como as unidades de saúde e os centros de referências, devem definir os profissionais responsáveis por cada etapa da atenção. Estas devem incluir entrevista inicial, exame clínico e ginecológico, exames complementares e acompanhamento psicológico.

Os fluxos de atendimento devem considerar condições especiais, como as intervenções de emergência ou a internação hospitalar. Além disso, figuram-se como forma de evitar que a usuária tenha de repetir sua história várias vezes para os diferentes profissionais da equipe ${ }^{(10)}$. No estudo, foi observado que após o contato inicial com a recepcionista, as mulheres eram encaminhadas ao acolhimento grupal. É importante ressaltar que a terapia em grupo visa colocar a mulher em contato com suas emoções e auxiliá-las no processo de transformação de sua realidade intra e interpsíquica, ou seja, a realidade relativa a ela e àqueles que a rodeiam em suas relações sociais $^{(11)}$. Essa interação permite que as usuárias troquem experiências e demonstrem emoções, antes presas, além de sentirem-se mais aliviadas por não estarem sós. 
Desta forma, as experiências com grupos de reflexão confirmam seu valor em fortalecer a autoestima entre as participantes ${ }^{(12)}$.

Por meio dos relatos, evidenciou-se, ainda, o acolhimento individual como forma de garantir a continuidade da assistência, cujos profissionais devem estar preparados e capacitados para tal procedimento. Destaca-se a atuação de enfermeiros, psicólogos e assistentes sociais, integrando a equipe do serviço, procurando garantir a qualidade e humanização da atenção.

Ressalta-se o papel da enfermagem no centro de referência que, apoiada no conhecimento científico e no senso comum. Esta contribui não somente para redução dos níveis de violência, como também se coloca na posição de mediadora na construção de uma rede de apoio que identifique, integre, articule e promova ações capazes de acolher à mulher nas diversas situações ${ }^{(13)}$. Outro profissional em destaque no atendimento à mulher vítima de violência é o defensor público. $\mathrm{O}$ aconselhamento jurídico é fundamental no combate à impunidade das vítimas, abrangendo desde orientações quanto à lavratura do boletim de ocorrência, como o acompanhamento nas fases de investigação, inquérito policial e ação penal ${ }^{(14)}$.

Além disso, a defensoria pública garante a proteção individual da vítima de violência perante a Lei Maria da Penha. Essa lei cria mecanismos para coibir e prevenir a violência doméstica e familiar contra a mulher, segundo a qual as mulheres gozam dos direitos fundamentais e inerentes à pessoa humana, sendo-lhes asseguradas as oportunidades e facilidades para viver sem violência, preservar a saúde física e mental e o aperfeiçoamento moral, intelectual e social ${ }^{(15)}$.

Os profissionais de nível médio e elementar também possuem papel importante na assistência à mulher vítima de violência. Nessa perspectiva, é relevante sensibilizar e capacitar motoristas, zeladores, vigilantes e agentes administrativos, mesmo que estes não atuem diretamente com a pessoa agredida, no tocante ao sigilo, ao acolhimento e a encaminhamentos adequados, a fim de que a vítima seja respeitada e valorizada como ser humano. O sigilo da informação e a privacidade do contexto da assistência multiprofissional são moderações éticas de confidencialidade das vítimas, como também precauções quanto à integridade física e emocional ${ }^{(10,16)}$.

Dentre as dificuldades apontadas pelos profissionais do centro de referência, destaca-se o constrangimento da mulher em procurar o serviço ou até mesmo em fornecer informações necessárias para melhor acompanhamento. Estima-se que a maioria das mulheres vítimas de violência não registre queixa por se sentirem humilhadas, ou por medo da reação do parceiro, dos familiares, dos amigos, dos vizinhos e das autoridades, sendo também comum a ameaça do agressor, caso seja revelado o ocorrido ${ }^{(12)}$.

Trabalhar com essa resistência é um dos maiores desafios para esses profissionais. Busca-se pela "perspectiva reversível", no sentido de perceber as verdades da vida que antes eram encobertas por distorções da realidade, passando a ter compreensão da vida mental e de mudança no modo de perceber as coisas ${ }^{(11)}$. As vítimas encontram dificuldades em romper com as situações de desrespeito e violência por acreditarem que os homens têm direito de fazer o que desejam, até mesmo puní-las, se pensam que elas fazem algo errado ou infligem às normas que eles determinam. Por isso, o processo de conscientização da mulher, na tentativa de mudar valores, é um dos maiores desafios para os profissionais, porque vai de encontro ao que as vítimas viam como 'algo natural' ${ }^{\prime(17)}$.

Outras dificuldades foram relatadas, desde os aspectos ligados às condições materiais para execução do trabalho até o insuficiente investimento na seleção e no acompanhamento dos recursos humanos, gerando impacto negativo nas instituições. Muitas vezes, os profissionais precisam complementar intervenções com auxílio de colegas de outras instituições, a fim de que o atendimento seja completo, principalmente na escassez de aparatos que impeçam o atendimento na própria instituição ${ }^{(12)}$.

Apesar do envolvimento dos diversos segmentos do governo e da sociedade civil em desempenhar articulação no combate à violência, percebe-se tendência ao isolamento dos serviços nos diferentes níveis de atenção. Desta forma, o trabalho em rede surge como proposta para superar a fragmentação dos serviços, visando à ampliação e melhoria da qualidade do atendimento; à identificação e encaminhamento adequado das mulheres em situação de violência; e ao desenvolvimento de estratégias efetivas de prevenção ${ }^{(8)}$.

Os profissionais definiram atuação em redes como método de trabalho importante, embora sua operacionalização fosse complexa, uma vez que trabalhar em rede pressupõe colocar em prática atitudes como a articulação entre instituições, visando proporcionar clima de sociabilidade e integração interinstitucional ${ }^{(12)}$. Nesse sentindo, a criação de fluxo de comunicação contínuo entre os atores envolvidos na rede, com o intuito de manter o processo de informação e referência 
e contrarreferência, é um desafio para os profissionais que atuam na assistência à mulher vítima de violência.

A Política Nacional de Enfrentamento à Violência contra as Mulheres propõe a constituição da rede de atendimento, buscando dar conta da complexidade da violência e do caráter multidimensional do problema, que perpassa diversas áreas, como saúde, educação, segurança pública, assistência social e cultura, entre outras $^{(8)}$. Entretanto, apesar de necessárias, as redes oficiais são pouco operativas, principalmente as de natureza pública, em virtude das implicações político-partidárias e dos procedimentos burocráticos que implicam na lentidão do atendimento ${ }^{(12)}$.

Instituem-se como importantes necessidades a formulação e a implantação de novas ações que integrem os diversos setores de maneira efetiva, modificando a assistência à mulher vítima de violência para atendimento não somente curativo ou reabilitador, como também para assistência preventiva, em que os riscos para ocorrência da violência sejam avaliados em cada realidade e que medidas preventivas possam ser tomadas antes da ocorrência da violência, e não apenas para a mulher, como também para a família ${ }^{(18)}$.

\section{CONCLUSÕES}

A violência contra a mulher é um problema que atinge não apenas a vítima em si, como também toda a rede social de apoio, exigindo o engajamento e a contribuição de diferentes profissionais capacitados e sensibilizados com a causa.

Cada profissional possui papel fundamental no fluxo de atendimento à mulher, que perpassa o acolhimento grupal e individual, as orientações jurídicas e a assistência indireta, como o serviço de transporte do Centro de Referência para a delegacia. Para atenção de qualidade, destaca-se a atuação da equipe multiprofissional com atuação interdisciplinar, visando ao resgate à autoestima e fortalecimento da vítima.

A maioria dos profissionais que trabalha com a problemática da violência contra a mulher encontra dificuldades em prestar assistência de qualidade, principalmente em função das barreiras colocadas pelas próprias vítimas, como o medo, a dependência financeira e emocional em relação ao agressor, fato que requer atendimento cuidadoso, a fim de que a mulher se sinta acolhida e não desista de buscar apoio. Além disso, a insuficiente integração da rede de saúde, a escassez de recursos humanos e materiais e a fragilidade que abate os profissionais refletem a realidade vivenciada em di- versos serviços de referência, sendo necessário, muitas vezes, improvisar para viabilizar o atendimento.

Sugere-se aos profissionais deste serviço e a outros com as mesmas características que observem atentamente e compreendam a importância da assistência multiprofissional no atendimento à mulher vítima de violência. Diante da complexidade da temática, urge maior interação da rede de atendimento com os serviços especializados, proporcionando à mulher atendimento humanizado e qualificado.

Apesar de o estudo fornecer considerações importantes em relação à assistência prestada à mulher vítima de violência, este se limitou a identificar o papel dos profissionais e conhecer as dificuldades enfrentadas. Logo, é fundamental que outros estudos busquem aprofundar as questões relacionadas às medidas preventivas e educativas realizadas à mulher e sua família, como forma de oferecer melhor suporte aos profissionais que lidam com a causa.

\section{REFERÊNCIAS}

1. Andrade CJM, Fonseca RMGS. Considerações sobre violência doméstica, gênero e o trabalho das equipes de saúde da família. Rev Esc Enferm USP. [Internet] 2008;42(3) [acesso em 12 jun 2011]. Disponível: http:// dx.doi.org/10.1590/S0080-62342008000300025.

2. Okabe I, Fonseca RMGS. Violência contra a mulher: contribuições e limitações do sistema de informação. Rev Esc Enferm USP. [internet] 2009;43(2) [acesso em 23 jul 2011]. Disponível: http://dx.doi.org/10.1590/ S0080-62342009000200027.

3. Franzoi NM, Fonseca RMGS, Guedes RN. Violência de gênero: concepções de profissionais das equipes de saúde da família. Rev. Latino-Am. Enfermagem [Internet] 2011;19(3) [acesso em 07 ago 2011]. Disponível: http:// dx.doi.org/10.1590/S0104-11692011000300019.

4. Pedrosa CM, Spink MJP. A violência contra mulher no cotidiano dos serviços de saúde: desafios para a formação médica. Saude soc. [Internet] 2011;20(1) [acesso em 10 ago 2011]. Disponível: http://dx.doi. org/10.1590/S0104-12902011000100015.

5. Peduzzi M. Equipe multiprofissional de saúde: conceito e tipologia. Rev. Saúde Públ. 2011;35(1):103-9.

6. Vieira LB, Padoin SMM, Landerdahl MC. A percepção de profissionais da saúde de um hospital sobre a violência contra as mulheres. Rev. Gaúcha Enferm. [Internet] 2009;30(4) [acesso em 10 ago 2011]. Disponível: http://seer.ufrgs.br/ RevistaGauchadeEnfermagem/article/view/9359/7536 
7. Silva LL, Coelho EBS, Caponi SNC. Violência silenciosa: violência psicológica como condição da violência física doméstica. Interface Comunic., Saude, Educ. [Internet] 2007;11(21) [acesso em 09 ago 2011]. Disponível: http:// dx.doi.org/10.1590/S1414-32832007000100009.

8. Secretaria Nacional de Enfrentamento à violência contra as mulheres (BR). Política Nacional de Enfrentamento à violência contra as mulheres. Brasília: Secretaria de Políticas para as Mulheres; 2011.

9. Bauer MW, Gaskell G. Pesquisa qualitativa com texto, imagem e som: um manual prático. $8^{\mathrm{a}}$ ed. Petrópolis: Vozes; 2010.

10. Ministério da Saúde (BR). Secretaria de Atenção à Saúde. Prevenção e Tratamento dos Agravos resultantes da violência sexual contra mulheres e adolescentes: Norma Técnica. Série A: Direitos sexuais e reprodutivos - Caderno n. 4. Brasília: MS; 2005.

11. Barone AR, Carvalho CV. O enfrentamento da violência contra a mulher: um resgate da autoestima. Revista Espaço Acadêmico [Internet]. 2009;8(95) [acesso em 10 out 2012]. Disponível: http://www.espacoacademico. com.br/095/95 barone-carval ho.ht m

12. Taquette S. Violência contra a mulher adolescente/ jovem. Rio de Janeiro: EdUERJ; 2007.

13. Budó MLD, Schimith MD, Silva DC, Silva SO, Rosa AS, Almeida PB. Percepções sobre a violência no cenário de uma unidade de saúde da família. Cogitare enferm. [Internet] 2012;17(1) [acesso em 08 out 2012]. Disponível: http://ojs.c3sl.ufpr.br/ojs2/index.php/ cogitare/article/view/26370/17563

14. Mattar R, Abrahão AR, Andalaft Neto J, Colas OR, Schroeder I, Machado SJR et al. Assistência multiprofissional à vítima de violência sexual: a experiência da Universidade Federal de São Paulo. Cad. Saúde Pública. 2007;23(2):459-64.

15. Brasil. Lei 11.340, de 7 de agosto de 2006. Cria mecanismos para coibir a violência doméstica e familiar contra a mulher, nos termos do $\S 8^{\circ}$ do art. 226 da Constituição Federal. Diário Oficial da República Federativa do Brasil, Brasília; 2006. Seção 1:1.

16. Schraiber LB, D’Oliveira AFPL, Couto MT. Violência e saúde: contribuições teóricas, metodológicas e éticas de estudos da violência contra a mulher. Cad. Saúde Pública. 2009;25(2):5-16.
17. Lima AC, Campos MCP. Violência contra a mulher: uma leitura de "Rappaccini's Daughter" e "The Birthmark”. Gláuks. 2007;7(2):71-7.

18. Costa AM, Moreira KAP, Henriques ACPT, Marques JF, Fernandes AFC. Violência contra a mulher: caracterização de casos atendidos em um centro estadual de referência. Rev. Rene. 2011;12(3):627-35. 